\title{
Effect of Perceived Organizational Virtuousness on Challenge-Oriented Organizational Citizenship Behavior: A Dual Mediation Model
}

\author{
Haotong Wang \\ Business Management, College of Business Administration, South China University of Technology, Guangzhou, China \\ Email: whtscut4453@163.com
}

How to cite this paper: Wang, H.T. (2018) Effect of Perceived Organizational Virtuousness on Challenge-Oriented Organizational Citizenship Behavior: A Dual Mediation Model. American Journal of Industrial and Business Management, 8, 1536-1548. https://doi.org/10.4236/ajibm.2018.86103

Received: May 24, 2018

Accepted: June 18, 2018

Published: June 21, 2018

Copyright $\odot 2018$ by author and Scientific Research Publishing Inc. This work is licensed under the Creative Commons Attribution International License (CC BY 4.0).

http://creativecommons.org/licenses/by/4.0/

\begin{abstract}
This study explores the internal mechanism between organizational morality perception and employee challenged organizational citizenship behavior and the internal mechanism based on the perspective of Chinese context and the integration of cognitive emotions. The results of multi-source tracking questionnaires show that: 1) Organizational moral awareness has a significant positive effect on employees' challenging organizational citizenship behavior; 2) Internal person identity and emotional commitment are perceived in organizational ethics and employees, respectively. The relationship between challenged organizational citizenship behaviors plays an intermediary role; 3) The recognition of insider identity and emotional commitment also play an intermediary role in the relationship between organizational moral awareness and employee challenge-based organizational citizenship behavior.
\end{abstract}

\section{Keywords}

Perceived Organizational Virtuousness, Perceived Insider Status, Affective Commitment, Challenge-Oriented Organizational Citizenship Behavior

\section{Introduction}

With the advent of economic globalization, mobile Internet, and big data era, enterprises in today's era can only win more respect by honoring ethics and shouldering more social responsibilities. Therefore, how to improve organization's competitiveness and achieve sustainable development by practicing organizational virtuousness has become an important issue for organization leaders and managers. As an important concept of combining positive psychology with business ethic, organizational ethics generally refers to the manifestation of indi- 
vidual (collective) behavior, organizational climate, organizational structure, active organizational policies, and procedures in organizations [1] [2]. At present, due to the unique role of organizational ethics in the promotion of organization and individual performance, more and more attention has been paid to the academic and practical communities. From another perspective, the changes in the corporate competitive environment have led to a greater proportion of role-based behaviors in the work of employees, and how to promote employee challenge-oriented organizational citizenship under brand-new working conditions (challenge-oriented organizational citizenship behavior, COCB) has also become the focus of the organization's human resource management. Challenging organizational citizenship behavior mainly refers to the creative idea expression and transformational effort that employees spontaneously generate to improve the operational efficiency of the organization [3]. In essence, it is clearly a category of positive behavior, which is closely related to the positivity of the internal and external organization of the individual [4]. Therefore, organizational ethics is likely to be an important antecedent variable for employees to challenge organizational citizenship behavior. Further literature studies indicate that although some studies have examined the relationship between organizational ethics and related outcomes, few studies have focused on the relationship between organizational ethics and challenging organizational citizenship behavior. Therefore, the primary purpose of this study is to explore the impact of organizational ethics on employee challenged organizational citizenship behavior in the context of China. In addition, it is also necessary to explore the internal mechanisms that influence organizational morality to influence employee-challenging organizational citizenship behavior. According to the cognitive-affective system theory (CAPS) perspective, individual behavior is influenced by the context and the cognitive-emotional interactions induced thereby. Therefore, this research selects the typical cognitive variables in the study of organizational behavior-perceived insider status and emotional state variables-affective commitment and assumes that the insider identity is cognitive and emotionally committed. The process of sexual influence on employees' challenging organizational citizenship plays an intermediary role. According to the view of Stamper and Masterson (2003) [5], the cognition of insider identity is whether the individual has perceived the status of the group membership within a specific organization. Previous studies have shown that cognition of insider identity is an important antecedent of individual performance [6]; Emotional Commitment reflects the individual's psychological acceptance and acceptance of organizational development direction and values [7]. Under normal circumstances, high emotional commitment and employee initiative to maintain organizational honor and willing to take corresponding actions for the development of the organization are closely related and ultimately affect the individual's behavioral performance [8] [9]. Therefore, whether the recognition of insider identity and emotional commitment play an intermediary role in the relation- 
ship between organizational ethics and challenged organizational citizenship is the second issue that this study needs to explore.

Based on the above analysis, this study will use the cognitive and emotional integration perspectives based on the Chinese context to explore the impact of organizational ethics on employee-challenged organizational citizenship behaviors, and the role that internal identity recognition and emotional commitment play in it. Theoretically, to make up for the deficiencies of previous studies, it is beneficial in practice to improve the organization's virtuous management level and further promote the role of employees outside the role.

\section{Theory and Assumptions}

\subsection{Organizing Virtue Perception and Challenge Organizational Citizenship Behavior}

Organizational ethics differs from the individual level in virtue of its focus on the individual's ethical quality. It reflects the overall ethical character of an organization. It is a reflection of the ethical quality of each individual, department, and organizational entity in the organization [2] [10]. Many studies have shown that organizational ethics can not only positively affect the positive emotions of individuals [11] and performance [12], but also can effectively predict the positive behavior of employees [13], so this study hypothesizes that organizational ethics may be an important pre-cause variable for employee challenged organizational citizenship behavior. Literature studies have shown that in organizations with a high degree of organizational ethics, individuals have a strong sense of identity with the organization's behavior and values, and are more willing to invest in actions to improve and promote organizational development [13]. Proactively put forward suggestions for improvement; in addition, further literature studies show that when employees sense higher levels of organizational ethics, they are more likely to form high-quality psychological contract relationships with the organization, in order to contribute to the organization and promote organizational change and development [14], thus willing to take on tasks that go beyond role responsibilities as well as challenging tasks. Based on the above analysis, this study proposes the following assumptions:

H1: Organizational morality perception significantly positively influences challenging organizational citizenship behavior.

\subsection{The Mediating Role of Insider Identity Cognition}

Combining Masterson and Stamper's (2003) [5] definition of insider identity, when employees classify themselves as "insiders", they will actively demonstrate extra-role behaviors that benefit the organization to improve their identity status [15]. As an out-of-play behavior, challenge-based organizational citizenship behaviors include transformative suggestions and innovative behaviors [16]. Studies at home and abroad have shown that internal person identities cognize the behaviors of advocating [17], innovation behavior [18] and organizational citi- 
zenship behavior [15] all have significant role in promoting. From this, it is predicted that the recognition of insider identity is one of the influencing factors that lead to the emergence of challenging organizational citizenship behavior.

The recognition of insider identity focuses on employees' social identity with the organization, and employees can realize the emotional and value implications of being a member of the organization [19]. Organizational virtue describes the noble moral qualities of the organization as a whole [2] and is considered to be the driving force behind the organization's prosperity and vitality [20]. The high quality of a virtuous organization is more likely to be recognized by employees [21], and the members of the organization are more tolerant, and employees can interact and interact frequently with the organization (or leaders) and other members. To obtain information or feedback, this not only gives employees and members of the organization a sense of intimacy and belonging, but also enables employees to more clearly understand the boundaries of the "insiders" and "outsiders" of the organization, and thus strengthens the employees' internal personalities. The perception of identity [6]. It can be inferred from this that the perception of organizational virtues helps to increase the awareness of employees' internal identities. In conjunction with the above analysis of the identity of insiders, this study proposes the following assumptions:

$\mathrm{H} 2$ : The recognition of insider identity plays an intermediary role in the relationship between the organization's perception of morality and the behavior of challenging organizational citizenship.

\subsection{The Mediating Role of Emotional Commitment}

Emotional commitment reflects the "degree of employee attachment, input, and emotional attachment to the organization" [22]. Previous studies have shown that emotional commitment can effectively predict the employee's willingness to leave [23], job performance [24], and extra-behavioral behavior [25], in which emotional commitment is positive to employee organizational citizenship behavior. The predictive effect has been verified many times [26] [27]. Specifically, employees with high emotional commitments will not only be satisfied with completing their own jobs, but will also make additional efforts to help and build the organization, so that such employees often show more challenging organizational citizenship behavior.

Although many scholars have explored the mechanism for the generation of emotional commitments, there are not many studies on the relationship between organizational ethics and organizational ethics. This study is based on social exchange theory, which assumes that the exchange relationship between employees and the organization abides by the principle of reciprocity [28] [29]. High morality organizations often make "deviations" conducive to their stakeholders and society [12], including caring for and helping their internal employees. Based on the principle of reciprocity, its employees are likely to repay the organization's gratitude by increasing their own recognition and commitment to the organiza- 
tion. High organizational ethical awareness thus strengthens employees' emotional commitment [11] [29]. In summary, the organization's perception of virtue is most likely to enhance employees' emotional commitment. Combining the relationship between employees' emotional commitment and organizational ethics and challenging organizational citizenship behavior, this study proposes the following assumptions:

H3a: Emotional Commitment plays an intermediary role in the relationship between organizational moral perceptions and challenging organizational citizenship behaviors.

In addition, when employees perceive their identities as internal members of the organization, they will inspire their responsibility as an insider [6] and emotional commitment to the organization [19] [30], which in turn promotes employees' challenging organizational behavioral citizenship behavior. Based on this, the study further proposes the following assumptions:

H3b: Cognition of insider identity and emotional commitment play an intermediary role in the relationship between organizational virtuous perception and challenging organizational citizenship behavior.

In summary, the theoretical model of this study is shown in Figure 1.

\section{Research Methods}

\subsection{Data Samples and Research Procedures}

This study used two-phase tracking questionnaires to collect data. First, the managers were randomly selected from the alumni of a college business school in South China and the students in the MBA classes to conduct surveys. At the same time, managers also need to randomly provide the researcher with a list of subordinates and a mailbox so that researchers can contact them. In order to better avoid common method variation, researchers used two time nodes for data collection: The variables for the first survey included organizational moral awareness, internal human identity, and emotional commitment, filled in by employees; the second survey was conducted at Three months after the end of the first survey, the manager evaluates the status of the challenging organizational citizenship behavior of his subordinates. The survey involved a total of 86 managers and 323 employees. In the end, 259 questionnaires were completely matched, and the ratio of leadership to employee questionnaires was 1:3.29.

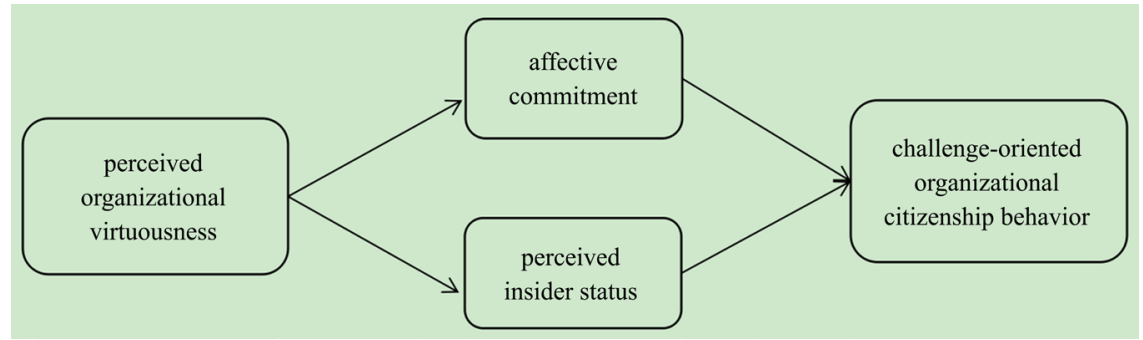

Figure 1. Theoretical model. 
According to the leading demographic variables, the male majority is $72.2 \%$; the average age is 37.98 ; the education level is mainly concentrated in the undergraduate and above; $85.3 \%$; according to the working years, less than 5 years account for $12.7 \%$, 5 years and above accounted for $87.3 \%$; most of them were middle managers, accounting for $40.9 \%$. According to the subordinate demographic variables, the majority of women are $59.3 \%$; the average age is 30.22 years; the education level is mainly concentrated in undergraduates accounted for $56.8 \%$; according to the number of years of work, 5 years and more than 5 years, accounting for $56.9 \%$.

\subsection{Variable Measurement}

\subsubsection{Organizational Virtue Perception}

The Organizational Virtue Perception Scale uses a five-dimension fifteen item scale developed by Solomon (1992) [31] and revised by Liu Yun (2015) [32]. The scale has a Cronbach's alpha value of 0.908 .

\subsubsection{Insider Identity Recognition}

The Internal Person Awareness Scale uses a single-dimension six-item scale developed by Stamper and Masterson (2002) [33]. The scale has a Cronbach's alpha value of 0.804 .

\subsubsection{Emotional Commitment}

The Emotion Commitment Scale uses the six-item unidimensional scale developed by Meyer and Allen (1993) [34]. The scale has a Cronbach's alpha value of 0.886 .

\subsubsection{Challenge Organizational Citizenship}

The Challenge Organizational Citizenship Behavior Scale uses the single-dimension five-item scale developed by MacKenzie, Podsakoff, and Podsakoff (2011) [35]. The scale has a Cronbach's alpha value of 0.741.

The above scales are all scored using the Likert five-point scale. The higher the score, the higher the level. The statistical analysis software used in this study was Mplus7.4 and SPSS 23.0.

\section{Data Analysis Results}

\subsection{Discriminant Validity and Homology Error Test}

The Harmon test showed that the first factor before rotation did not explain most of the variation $(28.094 \%)$. At the same time, the multicollinearity test found that the variance expansion coefficient (VIF) of this study variable was less than 2 and the tolerance between variables was greater than 0.9 , further confirmatory factor analysis competition model comparison results show that compared with other models, the fit of the benchmark model (four-factor model) is significantly better than other models (see Table 1), indicating the connotation of the variables in this study Independent and clear, good discriminant validity. 
Table 1. Confirmatory factor analysis results.

\begin{tabular}{cccccccc}
\hline Variable & $\chi^{2}$ & $d f$ & $X^{2} / d f$ & CFI & TLI & RMSEA & SRMR \\
\hline $\begin{array}{c}\text { Benchmark } \\
\text { model }\end{array}$ & 2251.430 & 693 & 3.248 & 0.923 & 0.908 & 0.026 & 0.020 \\
Three factors & 2406.233 & 706 & 3.408 & 0.887 & 0.856 & 0.092 & 0.033 \\
Three factors & 2376.768 & 706 & 3.366 & 0.878 & 0.796 & 0.076 & 0.040 \\
Three factors & 2455.276 & 706 & 3.477 & 0.826 & 0.826 & 0.104 & 0.038 \\
Two factors & 2559.324 & 719 & 3.559 & 0.846 & 0.809 & 0.095 & 0.034 \\
Single factor & 2711.077 & 732 & 3.704 & 0.805 & 0.767 & 0.108 & 0.041 \\
\hline
\end{tabular}

Note: Benchmark Models: Organizational Virtue Perception; Insider Identity Recognition; Emotional Commitment; Challenge Organizational Citizenship Behavior; The three-factor model: organizational moral perception; emotional commitment; internal person identity recognition + challenging organizational citizenship behavior; The three-factor model: organizational moral perception; inner person identity recognition; emotional commitment + challenging organizational citizenship behavior; Three-factor model: Organizational moral perception; Emotional commitment + inner person identity recognition; Challenge-based organizational citizenship behavior; Two-factor model: organization's perception of morality; recognition of insider identity + emotional commitment + challenging organizational citizenship behavior; Single-factor model: organizational moral perception + inner person identity recognition + emotional commitment + challenging organizational citizenship behavior.

The above analysis results show that the homologous method error (CMV) of this study has been well controlled.

\subsection{Hypothesis Testing}

The mean, standard deviation, and correlation coefficients for each variable in this study are shown in Table 2. Table 2 can be obtained, the main variables are related, and the validity of the variables is required to conduct the next study. At the same time, both the standard deviation and the average are also in line with the requirements for further research. The researchers used a multiple regression analysis method to test the proposed hypothesis. The specific results are shown in Table 3.

1) Main effect test: As can be seen from M3 in Table 3, the organization's perception of morality has a significant positive effect on the behavior of challenge-oriented organization citizens $(\beta=0.272, p<0.001)$, and $\mathrm{H} 1$ is supported; 2) The mediating effect test: From M6, when the organizational moral perception and emotional commitment are added, the direct effect of organizational moral perception on the challenge organizational citizenship behavior becomes insignificant (M6: $\beta=0.135, p>0.05$ ), from which emotional commitment can be fully mediated between the organization's perception of morality and challenged organizational citizenship behavior, $\mathrm{H} 3 \mathrm{a}$ is supported; when joined with the organization's perception of morality and internal person identity, despite organizational moral perception The direct effect on the challenge organizational citizenship behavior is still significant (M7: $\beta=0.221, p<0.001$ ), but the regression coefficient has declined, indicating that the internal person identity is perceived in organizational morality and in challenging organizational citizenship behavior. While playing part of the mediating role, $\mathrm{H} 2$ received support; 
Table 2. Descriptive statistics of research variables, correlation analysis results and internal consistency coefficient $(\mathrm{N}=259)$.

\begin{tabular}{|c|c|c|c|c|c|c|c|c|c|}
\hline Variable & 1 & 2 & 3 & 4 & 5 & 6 & 7 & 8 & 9 \\
\hline 1. Under attribute & - & & & & & & & & \\
\hline 2. Subordinate age & $-0.189^{* *}$ & - & & & & & & & \\
\hline 3. Subordinate education & -0.012 & 0.017 & - & & & & & & \\
\hline 4. Subordinate working years & $-0.159^{*}$ & $0.816^{* *}$ & -0.107 & - & & & & & \\
\hline 5. Subordinate position level & $-0.182^{\star *}$ & $0.420^{* *}$ & 0.026 & $0.381^{\star *}$ & - & & & & \\
\hline 6. POV & -0.079 & 0.002 & -0.098 & -0.031 & $0.151^{*}$ & - & & & \\
\hline 7. AC & $-0.166^{\star *}$ & 0.022 & $-0.137^{\star}$ & 0.049 & $0.142^{*}$ & $0.607^{* *}$ & - & & \\
\hline 8. PIS & 0.036 & 0.045 & $0.184^{* *}$ & 0.107 & 0.089 & $0.272^{* *}$ & $0.444^{\star *}$ & - & \\
\hline 9. $\mathrm{COCB}$ & $-0.238^{\star *}$ & 0.083 & -0.106 & 0.076 & $0.268^{\star *}$ & $0.319^{* *}$ & $0.364^{* *}$ & $0.257^{\star *}$ & - \\
\hline$M$ & 1.590 & 30.22 & 2.630 & 2.890 & 1.390 & 3.726 & 3.900 & 3.754 & 3.581 \\
\hline$S D$ & 0.492 & 60.543 & 0.781 & 10.358 & 0.642 & 0.547 & 0.577 & 0.674 & 0.551 \\
\hline
\end{tabular}

Note: ${ }^{* *}: p<0.01 ; *: p<0.05, \mathrm{POV}$ is organizational trait perception; PIS is internal person identity; AC is emotional commitment; COCB is challenge organizational citizenship behavior.

Table 3. Multiple regression analysis results.

\begin{tabular}{|c|c|c|c|c|c|c|c|c|}
\hline \multirow{2}{*}{ Variable } & \multicolumn{3}{|c|}{ PIS AC } & \multirow[b]{2}{*}{ M4 } & \multicolumn{4}{|c|}{$\mathrm{COCB}$} \\
\hline & M1 & M2 & M3 & & M5 & M6 & M7 & M8 \\
\hline 1. Under attribute & 0.102 & -0.119 & $-0.215^{\star *}$ & $-0.186^{* *}$ & $-0.251^{\star * \star}$ & -0.188 & -0.231 & $-0.206^{\star *}$ \\
\hline 2. Subordinate age & -0.012 & -0.011 & -0.003 & 0.001 & $0.164^{* \star *}$ & 0.168 & -0.001 & 0.157 \\
\hline $\begin{array}{l}\text { 3. Subordinate } \\
\text { education }\end{array}$ & $-0.117^{\star}$ & -0.029 & -0.067 & -0.064 & -0.058 & -0.060 & -0.049 & -0.049 \\
\hline $\begin{array}{l}\text { 4. Subordinate } \\
\text { working years }\end{array}$ & 0.102 & 0.058 & -0.002 & -0.025 & -0.035 & -0.015 & -0.018 & -0.023 \\
\hline $\begin{array}{l}\text { 5. Subordinate } \\
\text { position level }\end{array}$ & 0.029 & 0.036 & $0.180^{\star *}$ & $0.184^{\star *}$ & $0.208^{\star * *}$ & $0.172^{\star *}$ & $0.176^{\star *}$ & $0.171^{\star *}$ \\
\hline 6. POV & $0.326^{\star * *}$ & $0.608^{* * *}$ & $0.272^{\star * *}$ & & & 0.135 & $0.221^{* * *}$ & 0.134 \\
\hline 7. AC & & & & $0.302^{\star * *}$ & & $0.225^{\star *}$ & & $0.168^{*}$ \\
\hline 8. PIS & & & & & $0.203^{* * *}$ & & $0.154^{* *}$ & $0.110^{*}$ \\
\hline$\Delta \mathrm{R}^{2}$ & 0.121 & 0.382 & 0.193 & 0.215 & 0.181 & 0.226 & 0.224 & 0.239 \\
\hline Adjust $\mathrm{R}^{2}$ & 0.099 & 0.367 & 0.173 & 0.195 & 0.161 & 0.203 & 0.201 & 0.214 \\
\hline F value & $5.514^{* * *}$ & $24.874^{* *}$ & $9.622^{* * *}$ & $10.996^{* *}$ & $8.904^{* * *}$ & $10.008^{\star * *}$ & $9.878^{* * *}$ & $9.401^{* * *}$ \\
\hline
\end{tabular}

Note: ${ }^{* *}: p<0.001 ;{ }^{* *}: p<0.01 ;{ }^{*}: p<0.05$, POV is the perception of organizational virtue; PIS is the recognition of insider identity; AC is the emotional commitment; COCB is the challenge type Organizational citizenship.

after joining the organization's perception of morality, cognition of insider identity, and emotional commitment, the direct effect of organizational moral perception on challenge-based organizational citizenship behavior was not significant (M8: $\beta=0.134, p>0.05$ ), thus illustrating the perception and commitment of insider identity in organizational ethics and the relationship between war organization citizenship behavior plays an intermediary role, $\mathrm{H} 3 \mathrm{~b}$ supported. 
The researchers used the Bootstrap method and used the SPSS plug-in process developed by Preacher and Hayes (2008) [36] to further examine mediate effect significance and mediation path effect. It can be seen from Table 4 that path three, the organizational intuitionistic perception, through the emotional commitment, has a significant indirect effect on the challenge organizational citizenship behavior and does not include zero in the $99 \%$ confidence interval (CI $=$ $[0.1141,0.4121])$. H3a is once again validated; path two, the organization's perception of morality through in-house person identities, has a significant indirect effect on challenging organizational citizenship behaviors and does not include zero at the $99 \%$ confidence interval $(\mathrm{CI}=[0.0011,0.1481])$. H2 was further supported; at the same time, the indirect effect of Path IV, the recognition of inner person identity and emotional commitment in organizational moral perception and challenging organizational citizenship behavior was significant and was in the $99 \%$ confidence interval $(\mathrm{CI}=[0.0001,0.1151])$ does not contain zero, H3b gets further support.

\section{Discussion and Conclusion}

\subsection{Theoretical Significance}

First, this study selected less-recognized organizational moral perception as an antecedent variable that influences the behavior of challenge-based organizational citizens and found that organizational moral perception has a significant predictive effect on employees' challenging organizational citizenship behavior. This conclusion helps the academia and practice community have a deeper understanding of the relationship between organizational ethical personality characteristics and employee organizational behavior, and have enriched the research on the relationship between organizational moral perception and dependent variables; secondly, this study is based on Chinese context and will recognize and affect The combination of perspectives constitutes a cognitive-emotional dual-path integration model for the formation of challenging organizational citizenship behaviors. It was found that the individual's positive perceptions and emotions can positively affect the employee's challenging

Table 4. Mediating effect of the Bootstrap method and its confidence interval (5000 samples).

\begin{tabular}{cccc}
\hline Effect model & Action path & Effect size & BC 99\% CI \\
\hline $\begin{array}{c}\text { 1) Direct Effect (Path 1) } \\
\text { 2) Indirect Effect I } \\
\text { (Path 2) }\end{array}$ & POV $\rightarrow$ COCB & $0.314(51.31 \%)$ & {$[0.1631,0.5482]$} \\
$\begin{array}{c}\text { 3) Indirect Effect II } \\
\text { (Path 3) }\end{array}$ & POV $\rightarrow$ PIS $\rightarrow$ COCB $\rightarrow$ COCB & $0.038(6.21 \%)$ & {$[0.0011,0.1481]$} \\
$\begin{array}{c}\text { 4) Indirect Effect III } \\
\text { (Path 4) }\end{array}$ & POV $\rightarrow$ PIS $\rightarrow$ AC $\rightarrow$ COCB & $0.026(4.25 \%)$ & {$[0.0001,0.1151]$} \\
\hline
\end{tabular}

Note: POV is the perception of organization morality; PIS is the recognition of insider identity; AC is the emotional commitment; $\mathrm{COCB}$ is the challenge organizational citizenship behavior. 
organizational citizenship behavior. This finding helps to clarify the essence of the challenge-based organizational citizenship behavior. Finally, this study will have positive psychology and organization. The combination of behavior theory and application is an important extension of previous studies on the organizational perception of morality and challenging organizational citizenship behavior, and is helpful to further improve and deepen the theoretical study of related concepts.

\subsection{Practical Significance}

First of all, the study found that organizational morality perception is an important antecedent variable of employee challenge organizational citizenship behavior. Therefore, enterprises can improve organizational competitive advantage by selecting appropriate moral agents and establishing and perfecting institutionalized models that support moral behavior. Second, companies can increase employee self-perception in the organization through authorization and sharing of important information and resources; again, establish an organizational culture that is both fair and motivating, emphasizing the recognition of human resource management practices, and employees. Development and fair decision-making procedures and incentives are to enhance employees' identity and emotional attachment to the organization. Finally, establish a clear and optimistic vision for the organization and create a positive, open, and harmonious organizational atmosphere to increase employees' sense of pride, trust, and mission in the organization and inspire more challenging organizational citizenship behavior.

\subsection{Research Limitations and Future Research Directions}

There are some limitations in this paper: 1) Although we have used the two-stage multi-source tracking pairing method to collect data and tested for homogeneity variance, it is still not a longitudinal study in the strict sense, so future research needs to be adopted. More rigorous longitudinal research design and scenario experiments are used to further improve the accuracy of the conclusions; 2) The data in this study is mainly derived from the employees of enterprises in South China, so the external validity of the conclusions obtained will be affected in certain ways. Research can further expand the scope of sampling or survey specific industries to improve the external validity of the research findings; 3) This study explores the relationship between organizational moral perception and challenging organizational citizenship behavior based on the perspective of cognitive and emotional integration. Relationships, future research can try to explore the relationship between the two perspectives from different perspectives and further clarify the essence of organizational moral perceptions on employees' challenging organizational citizenship behavior.

\section{Conclusion}

This study examines and empirically examines emotional commitments and in- 
ternal person identity perceptions in organizing morality and corporate employees from the perspectives of both cognitive and emotional perspectives, and the main players and executives of employee challenged organizational citizenship behaviors. The mediating role of challenging organizational citizenship behaviors leads to the following conclusions: 1 ) organizational ethics has a significant positive impact on corporate citizens' challenged organizational citizenship behaviors, and emotional commitment has a positive effect on employees' challenged organizational citizenship behaviors; 2) the perception of insider identity has a significant impact on employees' challenging organizational citizenship behaviors; 3) Emotional commitment and internal person identity recognition play an intermediary role between organizational ethics and employee challenge-based organizational citizenship behavior.

\section{References}

[1] Liu, Y. (2012) Review and Prospect of Organizational Virtue Studies. Foreign Economics and Management, No. 2, 43-49.

[2] Bright, D.S., Cameron, K.S. and Caza, A. (2006) The Amplifying and Buffering Effects of Virtuousness in Downsized Organizations. Journal of Business Ethics, 64, 249-269. https://doi.org/10.1007/s10551-005-5904-4

[3] Seppälä, T., Lipponen, J., Bardi, A. and Pirttilä-Backman, A.M. (2012) Change-Oriented Organizational Citizenship Behaviour: An Interactive Product of Openness to Change Values, Work Unit Identification, and Sense of Power. Journal of Occupational and Organizational Psychology, 85, 136-155. https://doi.org/10.1111/j.2044-8325.2010.02010.x

[4] Fredrickson, B. (2001) The Role of Positive Emotions in Positive Psychology: The Broaden-and-Build Theory of Positive Emotions. American Psychologist, 56, 218-226. https://doi.org/10.1037/0003-066X.56.3.218

[5] Masterson, S.S. and Stamper, C.L. (2003) Perceived Organizational Membership: An Aggregate Framework Representing the Employee-Organization Relationship. Journal of Organizational Behavior, 24, 473-490. https://doi.org/10.1002/job.203

[6] Wang, J. and Kim, T.Y. (2013) Proactive Socialization Behavior in China: The Mediating Role of Perceived Insider Status and the Moderating Role of Supervisors' Traditionality. Journal of Organizational Behavior, 34, 389-406. https://doi.org/10.1002/job.1811

[7] Meyer, J.P. and Allen, N.J. (1997) Commitment in the Workplace: Theory, Research, and Application. Sage Publications, Thousand Oaks.

[8] Kazemipour, F. and Mohd, A.S. (2012) The Impact of Workplace Spirituality Dimensions on Organizational Citizenship Behavior among Nurses with the Mediating Effect of Affective Organizational Commitment. Journal of Nursing Management, 20, 1039-1048.

[9] Diedericks, E. and Rothmann, S. (2014) Flourishing of Information Technology Professionals: Effects on Individual and Organizational Outcomes. South African Journal of Business Management, 45, 27-41. https://doi.org/10.4102/sajbm.v45i1.115

[10] Cameron, K.S., Bright, D. and Caza, A. (2004) Exploring the Relationships between Virtuousness and Performance. American Behavioral Scientist, 47, 1-24. https://doi.org/10.1177/0002764203260209 
[11] Rego, A., Ribeiro, N., Cunha, M.P.E. and Jesuino, J.C. (2011) How Happiness Mediates the Organizational Virtuousness and Affective Commitment Relationship. Journal of Business Research, 64, 524-532. https://doi.org/10.1016/j.jbusres.2010.04.009

[12] Searle, T.P. and Barbuto, J.E. (2011) Servant Leadership, Hope, and Organizational Virtuousness: A Framework Exploring Positive Micro and Macro Behaviors and Performance Impact. Journal of Leadership \& Organizational Studies, 18, 107-117. https://doi.org/10.1177/1548051810383863

[13] Rego, A., Ribeiro, N. and Cunha, M. (2010) Perceptions of Organizational Virtuousness and Happiness as Predictors of Organizational Citizenship Behaviors. Journal of Business Ethics, 93, 215-235. https://doi.org/10.1007/s10551-009-0197-7

[14] Kooshki, A.S. and Zeinabadi, H. (2016) The Role of Organizational Virtuousness in Organizational Citizenship Behavior of Teachers: The Test of Direct and Indirect Effect through Job Satisfaction Mediating. International Review, 1-2, 7-21. https://doi.org/10.5937/intrev1602007K

[15] Hui, C., Lee, C. and Wang, H. (2015) Organizational Inducements and Employee Citizenship Behavior: The Mediating Role of Perceived Insider Status and the Moderating Role of Collectivism. Human Resource Management, 54, 439-456. https://doi.org/10.1002/hrm.21620

[16] Choi, J.N. (2007) Change-Oriented Organizational Citizenship Behavior: Effects of Work Environment Characteristics and Intervening Psychological Processes. Journal of Organizational Behavior, 28, 467-484. https://doi.org/10.1002/job.433

[17] Qian, S., Ding, M., Kong, W. and Wu, T. (2015) Leader-to-Subsidiary Exchanges, Internal Person Identity Recognition and Employee Advocacy-An Empirical Study of the Adjustment of Organizational Identity Attractiveness. Scientific Decision Making, No. 4, 1-20.

[18] Wang, Y., Cai, R. and Lin, X. (2014) The Relationship between the Cognition of Insider Identity and Innovative Behavior-A Model of Mediated Mediating Effect. Foreign Economics and Management, 36, 40-53.

[19] Chen, Z.X. and Aryee, S. (2007) Delegation and Employee Work Outcomes: An Examination of the Cultural Context of Mediating Processes in China. Academy of Management Journal, 50, 226-238. https://doi.org/10.5465/amj.2007.24162389

[20] Cameron, K.S. and Caza, A. (2004) Contributions to the Discipline of Positive Organizational Scholarship. American Behavioral Scientist, 47, 731-739. https://doi.org/10.1177/0002764203260207

[21] Tsachouridi, I. and Nikandrou, I. (2016) Organizational Virtuousness and Spontaneity: A Social Identity View. Personnel Review, 45, 1302-1322.

https://doi.org/10.1108/PR-09-2014-0192

[22] Allen, N.J. and Meyer, J.P. (1990) The Measurement and Antecedents of Affective, Continuance and Normative Commitment to the Organization. Journal of Occupational and Organizational Psychology, 63, 1-18.

https://doi.org/10.1111/j.2044-8325.1990.tb00506.x

[23] Poon, J.M.L. (2012) Distributive Justice, Procedural Justice, Affective Commitment, and Turnover Intention: A Mediation-Moderation Framework. Journal of Applied Social Psychology, 42, 1505-1532. https://doi.org/10.1111/j.1559-1816.2012.00910.x

[24] Vandenberghe, C., Bentein, K. and Stinglhamber, F. (2004) Affective Commitment to the Organization, Supervisor, and Work Group: Antecedents and Outcomes. Journal of Vocational Behavior, 64, 47-71. https://doi.org/10.1016/S0001-8791(03)00029-0 
[25] Lavelle, J.J. (2010) What Motivates OCB? Insights from the Volunteerism Literature. Journal of Organizational Behavior, 31, 918-923. https://doi.org/10.1002/job.644

[26] Norris-Watts, C. and Levy, P.E. (2004) The Mediating Role of Affective Commitment in the Relation of the Feedback Environment to Work Outcomes. Journal of Vocational Behavior, 65, 351-365. https://doi.org/10.1016/j.jvb.2003.08.003

[27] Liu, Y. and Zhou, Z. (2015) Employee-Perceived Relationships between Corporate Social Responsibility, Emotional Commitment and Organizational Citizenship Behavior-The Cross-Layered Regulatory Role of Committed Human Resource Practices. Management Review, 27, 118-127.

[28] Lee, J. and Peccei, R. (2007) Perceived Organizational Support and Affective Commitment: The Mediating Role of Organization-Based Self-Esteem in the Context of Job Insecurity. Journal of Organizational Behavior, 28, 661-685.

https://doi.org/10.1002/job.431

[29] Choi, D., Oh, I.S. and Colbert, A.E. (2015) Understanding Organizational Commitment: A Meta-Analytic Examination of the Roles of the Five-Factor Model of Personality and Culture. Journal of Applied Psychology, 100, 1542-1567. https://doi.org/10.1037/apl0000014

[30] Lapalme, M.Ė., Stamper, C.L., Semard, G. and Tremblay, M. (2009) Bringing the Outside in: Can "External” Workers Experience Insider Status? Journal of Organizational Behavior, 30, 919-940. https://doi.org/10.1002/job.597

[31] Solomon, R.C. (1992) Ethics and Excellence: Cooperation and Integrity in Business. Oxford University Press, Oxford.

[32] Liu, Y. (2015) Conceptual Connotation, Structure Dimensions, and Scale Verification of Organizational Virtues. Accounting and Economic Studies, No. 3, 101-112.

[33] Stamper, C.L. and Masterson, S.S. (2002) Insider or Outsider? How Employee Perceptions of Insider Status Affect Their Work Behavior. Journal of Organizational Behavior, 23, 875-894. https://doi.org/10.1002/job.175

[34] Meyer, J.P., Allen, N.J. and Smith, C.A. (1993) Commitment to Organizations and Occupations: Extension and Test of a Three-Point Conceptualization. Journal of Applied Psychology, 78, 538-551. https://doi.org/10.1037/0021-9010.78.4.538

[35] Mackenzie, S.B., Podsakoff, P.M. and Podsakoff, N.P. (2011) Challenge-Oriented Organizational Citizenship Behaviors and Organizational Effectiveness: Do Challenge-Oriented Behaviors Really Have an Impact on the Organization's Bottom Line? Personnel Psychology, 64, 559-592. https://doi.org/10.1111/j.1744-6570.2011.01219.x

[36] Preacher, K.J. and Hayes, A.F. (2008) Asymptotic and Resampling Strategies for Assessing and Comparing Indirect Effects in Multiple Mediator Models. Behavior Research Methods, 40, 879-891. https://doi.org/10.3758/BRM.40.3.879 